\title{
Variability in surgical management of kidney cancer between urban and rural hospitals in Queensland, Australia: a population- based analysis
}

\author{
Megan K. Forbes ${ }^{1}$, Evan P. Owens ${ }^{1,2}$, Simon T. Wood $^{1,3}$, Glenda C. Gobe ${ }^{1,2,4}$, Robert J. Ellis ${ }^{1,3,4}$ \\ ${ }^{1}$ Centre for Kidney Disease Research, University of Queensland, Translational Research Institute, Brisbane, Australia; ${ }^{2}$ NHMRC Chronic Kidney \\ Disease Centre for Research Excellence, University of Queensland, Brisbane, Australia; ${ }^{3}$ Department of Urology, Princess Alexandra Hospital, \\ Brisbane, Australia; ${ }^{4}$ School of Biomedical Sciences, University of Queensland, Brisbane, Australia \\ Contributions: (I) Conception and design: ST Wood, RJ Ellis; (II) Administrative support: ST Wood, GC Gobe, RJ Ellis; (III) Provision of study \\ materials or patients: RJ Ellis; (IV) Collection and assembly of data: MK Forbes, EP Owens, RJ Ellis; (V) Data analysis and interpretation: All \\ authors; (VI) Manuscript writing: All authors; (VII) Final approval of manuscript: All authors. \\ Correspondence to: Robert J. Ellis. Centre for Kidney Disease Research, University of Queensland, Lvl 5 Translational Research Institute, \\ Woolloongabba QLD 4102, Brisbane, Australia. Email: r.ellis1@uq.edu.au.
}

Background: International guidelines recommend partial over radical nephrectomy for management of kidney tumours, due to perceived advantages of kidney function preservation. In Queensland, oncological nephrectomy is performed in both metropolitan and rural hospitals. Previous studies have shown that patients from rural areas with kidney tumours are less likely to undergo partial nephrectomy compared with those in major cities. The aim of this study was to investigate patterns of partial nephrectomy according to geographical area, and to identify patient- and health-service-level characteristics associated with partial nephrectomy.

Methods: All 3,799 incident kidney cancer cases in Queensland (Jan 2009 to Dec 2014) were ascertained. Patients aged $<18$ yrs ( $n=47)$, who did not receive surgery ( $\mathrm{n}=988)$, or had end-stage kidney disease (ESKD) before surgery $(n=17)$ were excluded. The final sample included 2,747 patients. Data were analysed using multivariable logistic regression in order to identify associations with partial nephrectomy.

Results: Of 2,747 patients, 637 (25\%) underwent partial nephrectomy. The likelihood of undergoing partial nephrectomy increased with more recent year of surgery $(\mathrm{P}<0.001)$ and higher socioeconomic status $(\mathrm{P}<0.001)$. The likelihood of undergoing partial nephrectomy decreased for patients managed in lower-volume centres $(\mathrm{P}=0.004)$, with increasing age $(\mathrm{P}<0.001)$, and hospital location outside of a major city $(\mathrm{P}<0.001)$. Overall, the number of nephrectomies, and proportion/number of partial nephrectomies, performed in rural hospitals has increased over the study period.

Conclusions: Our results suggest that, although patients who are managed in major cities are more likely to undergo partial nephrectomy, likelihood of undergoing partial nephrectomy in rural centres is increasing, consistent with international best practice.

Keywords: Hospital volume; nephrectomy; partial nephrectomy; renal cell carcinoma; rural hospital; socioeconomic status

Submitted Nov 22, 2019. Accepted for publication Feb 25, 2020.

doi: $10.21037 /$ tau-19-775

View this article at: http://dx.doi.org/10.21037/tau-19-775 


\section{Introduction}

The kidney is the ninth most common site of primary cancer in Australia, and incidence is increasing (1); agestandardised incidence rates have risen from 6.2 per 100,000 in 1982 , to 12.4 per 100,000 in 2017 (2). Most kidney cancers are managed surgically, through resection of all (radical nephrectomy) or part (partial nephrectomy) of the cancer-affected kidney. Although these procedures have similar oncological outcomes $(3,4)$, partial nephrectomy is recommended by international guidelines when technically feasible, due to perceived benefits with respect to nephron preservation leading to better postoperative kidney function $(5,6)$.

The number of partial nephrectomies being performed for management of kidney tumours has increased globally, as evidenced by studies from the USA (7-10), Europe (11-13), Canada (14), and Australia (15-17). A number of studies have also evaluated factors associated with undergoing partial nephrectomy. Common findings of these studies were that larger hospital volumes, higher socioeconomic status, and more recent year of surgery were associated with a higher likelihood of partial nephrectomy; and older age and non-metropolitan residence were associated with a lower likelihood of undergoing partial nephrectomy $(7,15,16)$.

The aim of this study was to explore associations between patient- and hospital-level characteristics and the likelihood of undergoing partial nephrectomy in Queensland, with particular focus on how geographical factors affected the type of surgical management.

\section{Methods}

All 3,799 patients diagnosed with kidney cancer between January 2009 and December 2014 in Queensland (Australia) were identified using the Queensland Cancer Registry. Reporting cancer incidence to state-based registries is a legal requirement in Australia, therefore ascertainment of all cases is likely close to complete. Patients who were aged $<18$ yrs $(\mathrm{n}=47)$, did not receive surgery ( $\mathrm{n}=988)$, or had endstage kidney disease (ESKD) before surgery $(n=17)$ were excluded. Patients who had ESKD before surgery were identified using administrative data linked to international classification of disease-10 codes, per our previous study (18). The final sample included 2,747 patients.

Data were extracted from the Queensland Cancer
Registry on the $14^{\text {th }}$ of September 2017 , and linked to electronic hospital admission and discharge data as previously described (18). American Society of Anesthesiologists (ASA) classification was recorded at the time of surgery, and linked to cancer registry data from hospital records, before being provided to investigators. ASA classification was grouped as $1-2$ and $\geq 3$. Urban/rural place of residence and hospital location were assigned based on the Accessibility/Remoteness Index of Australia (19), and grouped as major city, inner regional, and rural (outer regional/remote/very remote). Patients were evaluated by area-level socioeconomic status, grouped by tertiles (disadvantaged/middle/advantaged) based on the Australian Socioeconomic Indexes for Areas (Index of Relative Socioeconomic Disadvantage) (20). Patientlevel socioeconomic status and urban/rural status were determined from the postcode of the patient's usual place of residence recorded in the cancer registry, and provided in the data extract. Hospital location was also assigned based on postcode. Hospital volume was reported as the average number of cases/yr, estimated by dividing the total number of oncological nephrectomies performed during the study period at each centre by the length of the study period (6 yrs).

The main outcome was whether a patient was managed with partial nephrectomy. Multivariable logistic regression was used to evaluate whether various patient- and hospitallevel characteristics affected the likelihood of undergoing partial nephrectomy. Models were adjusted only for potential confounders, identified using directed acyclic graphs. When adjusting for health-service characteristics, clustering by hospital code was accounted for using robust sandwich estimators. Analysis was performed using Stata 14.0 (StataCorp, College Station, TX, USA).

To evaluate the geographical distribution of kidney cancer cases in Queensland, cases that were managed surgically during the study period were grouped by geographical region (Statistical Area Level 2-Australian Bureau of Statistics), with rates standardised to the 2011 population of each area. This was visualised with a heat map generated using Microsoft Excel (Microsoft Corporation, Albuquerque, NM, USA). Geographical boundaries were imported from the Australian Bureau of Statistics data cube "Statistical Area Level 2 (SA2) ASGS Ed 2016 Digital Boundaries in ESRI Shapefile Format" (http://www.abs.gov.au/AUSSTATS/abs@.nsf/ 
DetailsPage/1270.0.55.001July\%202011). A map showing hospitals in Queensland that performed a nephrectomy during the study period was produced using Google Maps.

\section{Results}

Characteristics of the study population are presented in Table 1. Of 2,747 included patients, 637 were managed with partial nephrectomy (25\%). The cohort was predominantly male (65\%), and the median age was $62 \mathrm{yrs}$.

Associations between patient- and hospital-level characteristics and partial nephrectomy are presented in Table 2. Of the patient-level characteristics, age (per 5 yrs) was negatively associated with the likelihood of undergoing partial nephrectomy [odds ratio (OR): $0.86,95 \%$ confidence interval $(\mathrm{CI})$ : $0.83-0.89, \mathrm{P}<0.001]$, and patients residing in areas considered to have a higher socioeconomic status (advantaged/middle) had a higher likelihood of undergoing partial nephrectomy compared with those living in low socioeconomic status areas (disadvantaged) (OR: 1.9, 95\% CI: $1.4-2.5$ and OR: 1.2, 95\% CI: $0.9-1.5$ for advantaged and middle, respectively, $\mathrm{P}=0.004)$. The patient's usual place of residence also affected likelihood of being managed with partial nephrectomy, where patients who lived in inner regional/rural areas were less likely to undergo partial nephrectomy compared with patients who lived in major cities (OR: 0.7, 95\% CI: 0.6-0.9 and OR: 0.7, 95\% CI: 0.51.0 , respectively, $\mathrm{P}=0.01$ ). Sex and ASA classification were not associated with partial nephrectomy.

When considering hospital-level characteristics, hospital location and volume were associated with partial nephrectomy. Compared with being managed in hospitals located in major cities, management in hospitals in inner and outer regional areas was associated with a lower likelihood of undergoing partial nephrectomy (OR: $0.4,95 \%$ CI: $0.2-0.7$ and OR: $0.3,95 \%$ CI: $0.2-$ 0.7 , respectively, $\mathrm{P}<0.001)$. Compared with hospitals performing $>20$ oncological nephrectomies per year, being managed at hospitals with lower annual caseloads (1-10 and 11-20 cases/yr) was also associated with lower likelihood of undergoing partial nephrectomy (OR: 0.4, 95\% CI: $0.2-0.9$ and OR: $0.7,95 \%$ CI: $0.3-1.5$, respectively, $\mathrm{P}=0.004)$. More contemporary year of surgery was associated with a higher likelihood of undergoing partial nephrectomy $(\mathrm{P}<0.001)$ (Figure 1). Hospital type (public/private) did not significantly affect the likelihood of undergoing partial nephrectomy.
Characteristics of patients compared by hospital location are presented in Table 3. Changes in the number/proportion of partial nephrectomies performed over time compared by hospital location is presented in Figure 2. The number of cases performed at outer regional hospitals more than doubled between 2009 and 2014, and the proportion of partial nephrectomies increased from $<1 \%$ to $21 \%$ over the same period.

Maps showing the rates of kidney cancer surgery per 100,000 population specific to individual statistical areas in Queensland, the geographical distribution of Australia's population in general, and the distribution of hospitals which performed a nephrectomy during the study period in Queensland is presented in Figure 3.

\section{Discussion}

The aim of this study was to identify characteristics associated with undergoing partial compared with radical nephrectomy in patients managed surgically for kidney cancer in Queensland, with a particular focus on how geographical factors affected management. Of the patientlevel characteristics, older age, rural place of residence, and lower socioeconomic status were associated with a lower likelihood of undergoing partial nephrectomy. Of the hospital-level characteristics, this study found that being managed in hospitals in metropolitan areas and at hospitals with higher caseloads was associated with a higher likelihood of undergoing partial nephrectomy.

The findings that partial nephrectomy was more likely at metropolitan hospitals and hospitals with higher caseloads most likely reflects similar information, as metropolitan hospitals tend to be higher-volume. Similarly, the finding that patients whose usual place of residence was outside a major city were more likely to undergo radical nephrectomy is also likely to reflect the fact that these patients were more likely to be managed at hospitals outside a major city. These findings are unsurprising, and consistent with studies conducted elsewhere in Australia and internationally. A population-based study of 1,836 patients who were managed surgically for renal cell carcinoma in Victoria (Australia) in 2009, 2012 and 2013 reported increased likelihood of undergoing partial nephrectomy in hospitals where more than 30 nephrectomies were performed per year (OR: 1.4, 95\% CI: 0.9-2.2) compared with 1-14 nephrectomies per year, and decreased likelihood of partial nephrectomy with place of residence outside a major city (OR: 0.8, 95\% 
Table 1 Characteristics of 2,747 patients managed surgically for kidney cancer

\begin{tabular}{|c|c|c|}
\hline Parameters & Partial nephrectomy ${ }^{a}(\mathrm{n}=637)$ & Radical nephrectomy ${ }^{a}(n=2,110)$ \\
\hline$<65$ & $447[70]$ & $1,192[56]$ \\
\hline$\geq 65$ & $190[30]$ & 918 [44] \\
\hline Median [IQR] & 63 [54-71] & 59 [49-67] \\
\hline \multicolumn{3}{|l|}{ Year of surgery } \\
\hline 2010 & 82 [13] & 308 [15] \\
\hline 2011 & 85 [13] & $351[17]$ \\
\hline 2012 & 97 [15] & 364 [17] \\
\hline Female & 202 [32] & 748 [35] \\
\hline Male & $435[68]$ & $1,362[65]$ \\
\hline \multicolumn{3}{|l|}{ ASA classification } \\
\hline $1-2$ & $336[64]$ & $1,102[60]$ \\
\hline$\geq 3$ & $190[36]$ & 738 [40] \\
\hline \multicolumn{3}{|c|}{ Socioeconomic status ${ }^{b}$} \\
\hline Disadvantaged & 123 [19] & $506[24]$ \\
\hline Middle & 391 [61] & $1,351[64]$ \\
\hline \multicolumn{3}{|l|}{ Hospital type } \\
\hline Public & $318[50]$ & 953 [45] \\
\hline Private & $319[50]$ & 1157 [55] \\
\hline \multicolumn{3}{|l|}{ Hospital location ${ }^{c}$} \\
\hline Major city & 578 [91] & $1,641[78]$ \\
\hline Inner regional & $38[6]$ & 327 [16] \\
\hline Rural & $21[3]$ & $142[7]$ \\
\hline \multicolumn{3}{|c|}{ Hospital volume, resections/yr ${ }^{\mathrm{d}}$} \\
\hline $1-10$ & $49[8]$ & 417 [20] \\
\hline $11-20$ & 114 [18] & $414[20]$ \\
\hline$>20$ & $474[74]$ & $1,279[60]$ \\
\hline
\end{tabular}

Data presented as: count [\%] or median [interquartile range]. ${ }^{a}$, Nephrectomy type taken from the first procedure only; ${ }^{b}$, socioeconomic indexes for areas index of relative socioeconomic advantage and disadvantage (tertiles); ${ }^{c}$, accessibility/remoteness index of Australia; rural encompasses outer regional and remote categories; ${ }^{d}$, number of surgeries for kidney cancer at each centre per year. IQR, interquartile range; ASA, American Society of Anesthesiologists. 
Table 2 Associations between patient- and hospital-level characteristics and partial nephrectomy

\begin{tabular}{|c|c|c|}
\hline Characteristics & Crude, OR (95\% Cl) & Adjusted, OR (95\% Cl) \\
\hline \multicolumn{3}{|c|}{ Age at diagnosis, year } \\
\hline$<65$ & Reference & Reference \\
\hline$\geq 65$ & $0.6(0.5-0.7)$ & $0.6(0.5-0.7)$ \\
\hline$P$ value & $<0.001$ & $<0.001$ \\
\hline Per 5 years & $0.9(0.8-0.9)$ & $0.9(0.8-0.9)$ \\
\hline$P$ value & $<0.001$ & $<0.001$ \\
\hline
\end{tabular}

Year of surgery

$\begin{array}{lc}2009 & \text { Reference } \\ 2010 & 1.3(0.9-1.9) \\ 2011 & 1.2(0.8-1.7) \\ 2012 & 1.3(0.9-1.9) \\ 2013 & 2.1(1.6-3.0) \\ 2014 & 1.9(1.4-2.6) \\ \text { P value } & <0.001\end{array}$

Sex

$\begin{array}{lc}\text { Female } & \text { Reference } \\ \text { Male } & 1.2(1.0-1.4) \\ \text { P value } & 0.08\end{array}$

ASA classification

$\begin{array}{lcc}1-2 & \text { Reference } & \text { Reference } \\ \geq 3 & 0.8(0.7-1.0) & 1.0(0.8-1.3) \\ P \text { value } & 0.10 & 0.80\end{array}$

Socioeconomic status

$\begin{array}{lcc}\text { Disadvantaged } & \text { Reference } & \text { Reference } \\ \text { Middle } & 1.2(0.9-1.5) & 1.2(0.9-1.5) \\ \text { Advantaged } & 2.0(1.5-2.7) & 1.9(1.4-2.5) \\ \text { P value } & <0.001 & <0.001\end{array}$

Place of residence ${ }^{\mathrm{a}}$

$\begin{array}{lcc}\text { Major city } & \text { Reference } & \text { Reference } \\ \text { Inner regional } & 0.7(0.5-0.8) & 0.7(0.6-0.9) \\ \text { Rural } & 0.8(0.6-1.0) & 0.7(0.5-1.0) \\ P \text { value } & <0.001 & 0.01\end{array}$

Table 2 (continued)
Table 2 (continued)

\begin{tabular}{lcc}
\hline Characteristics & Crude, OR $(95 \% \mathrm{Cl})$ & Adjusted, OR $(95 \% \mathrm{Cl})$ \\
\hline Hospital type $^{\mathrm{b}}$ & Reference & Reference \\
Public & $1.2(0.7-2.1)$ & $1.2(0.7-2.1)$ \\
Private & 0.51 & 0.55 \\
P value & & \\
Hospital location ${ }^{\mathrm{C}}$ & Reference & Reference \\
Major city & $0.3(0.2-0.6)$ & $0.4(0.2-0.7)$ \\
Inner regional & $0.4(0.2-0.9)$ & $0.3(0.2-0.7)$ \\
Rural & $<0.001$ & $<0.001$ \\
P value & Reference & \\
Hospital volume, resections/yr & \\
$1-10$ & $0.3(0.2-0.6)$ & $0.4(0.2-0.9)$ \\
$11-20$ & $0.7(0.4-1.6)$ & $0.7(0.3-1.5)$ \\
$>20$ & $<0.001$ & 0.004 \\
P value & Reference
\end{tabular}

OR and $95 \% \mathrm{Cl}$ estimated using multivariable regression models. All adjusted estimates were adjusted for age and sex; additional adjustment variables are included as footnotes. For hospital type, location, and volume, clustering by hospital code was accounted for using robust sandwich estimators. a , Additionally adjusted for ASA classification; ${ }^{b}$, additionally adjusted for ASA classification and socioeconomic status; c, additionally adjusted for ASA classification and SES; ${ }^{d}$, additionally adjusted for ASA classification, hospital type, and hospital region. OR, odds ratio; $\mathrm{Cl}$, confidence interval; $\mathrm{ASA}$, American Society of Anesthesiologists.

CI: 0.5-1.1) (15). A similar study from New South Wales (Australia) analysed data from 3,771 patients with newly diagnosed localised kidney cancer from 2001-2009 also found that being managed with partial nephrectomy was more likely in hospitals where more than 8 oncological nephrectomies were performed per year (OR: 2.4, 95\% CI: 1.5-3.8), compared with less than 2 per year (16). Increased likelihood of partial nephrectomy with higher hospital volume was also reported in studies of different populations in the US (7,8), and Europe (11). A US study using the Nationwide Inpatient Sample data, which includes selected all-payer hospitals, representing about $20 \%$ of all US hospitals, reported that patient residence in an urban setting also had increased likelihood of partial nephrectomy (7). 


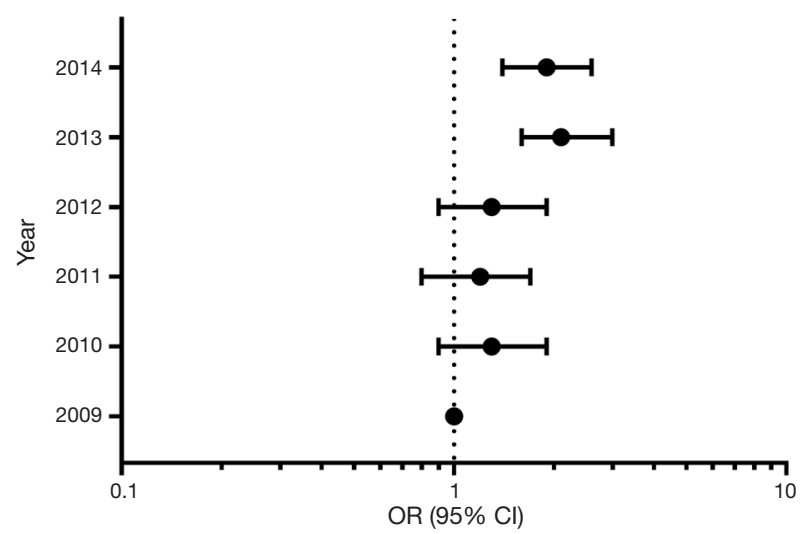

Figure 1 Likelihood of partial nephrectomy in Queensland by year. Likelihood of partial nephrectomy compared by year. Data presented as crude OR and 95\% CI, considering the year 2009 as the reference. OR, odds ratio; CI, confidence interval.
There are many reasons why management at rural and smaller-volume hospitals may lead to a lower likelihood of undergoing partial nephrectomy, which could relate to inequality of resource allocation, as well as staffing and infrastructural limitations (21). As partial nephrectomy is generally more technically-difficult than radical nephrectomy, and this difficulty can be compounded by both tumour factors (e.g., size and location relative to vessels and collecting system) and patient factors (e.g., comorbidities and functional status), it is conceivable that medically complex cases were referred to a tertiary centre located in a major city. This is likely to have driven down the percentage of partial nephrectomies performed in regional centres. Although data on tumour factors were not available, the fact that most patients who underwent partial nephrectomy in a rural setting had an ASA score of

Table 3 Patient and health-service characteristics compared by hospital location

\begin{tabular}{|c|c|c|c|c|}
\hline Variables & All $(n=2,747)$ & Major city $(n=2,219)$ & Inner regional $(\mathrm{n}=365)$ & Outer regional $(n=163)$ \\
\hline \multicolumn{5}{|l|}{ Age, year, n [\%] } \\
\hline$<50$ & $490[18]$ & $415[19]$ & $56[13]$ & 29 [18] \\
\hline $50-59$ & $679[25]$ & $547[25]$ & $89[24]$ & $43[26]$ \\
\hline $60-69$ & $836[30]$ & $684[31]$ & $113[31]$ & 39 [24] \\
\hline$\geq 70$ & $742[27]$ & $573[26]$ & 117 [32] & 52 [32] \\
\hline \multicolumn{5}{|l|}{ Sex, n [\%] } \\
\hline Female & $950[35]$ & 767 [35] & $135[37]$ & 48 [29] \\
\hline Male & $1,797[65]$ & $1,452[65]$ & $230[63]$ & $115[71]$ \\
\hline \multicolumn{5}{|l|}{ ASA score, n [\%] } \\
\hline $1-2$ & $1,438[52]$ & $1,118[50]$ & $241[66]$ & $79[48]$ \\
\hline$\geq 3$ & 928 [34] & $773[35]$ & $108[30]$ & 47 [29] \\
\hline Missing & $381[14]$ & $328[15]$ & $16[4]$ & 37 [23] \\
\hline \multicolumn{5}{|c|}{ Socioeconomic status, $\mathrm{n}[\%]$} \\
\hline Disadvantaged & $629[23]$ & $487[22]$ & 105 [29] & 37 [23] \\
\hline Middle & $1,742[63]$ & $1,369[62]$ & $257[70]$ & $116[71]$ \\
\hline Advantaged & $376[14]$ & $363[16]$ & $3[1]$ & $10[6]$ \\
\hline \multicolumn{5}{|l|}{ Place of residence, $n$ [\%] } \\
\hline Major city & $1,663[61]$ & $1,524[69]$ & $138[38]$ & $1[<1]$ \\
\hline Inner regional & $667[24]$ & $453[20]$ & $201[55]$ & $13[8]$ \\
\hline Outer regional/remote & $417[15]$ & $242[11]$ & $26[7]$ & 149 [91] \\
\hline
\end{tabular}

ASA, American Society of Anesthesiologists. 

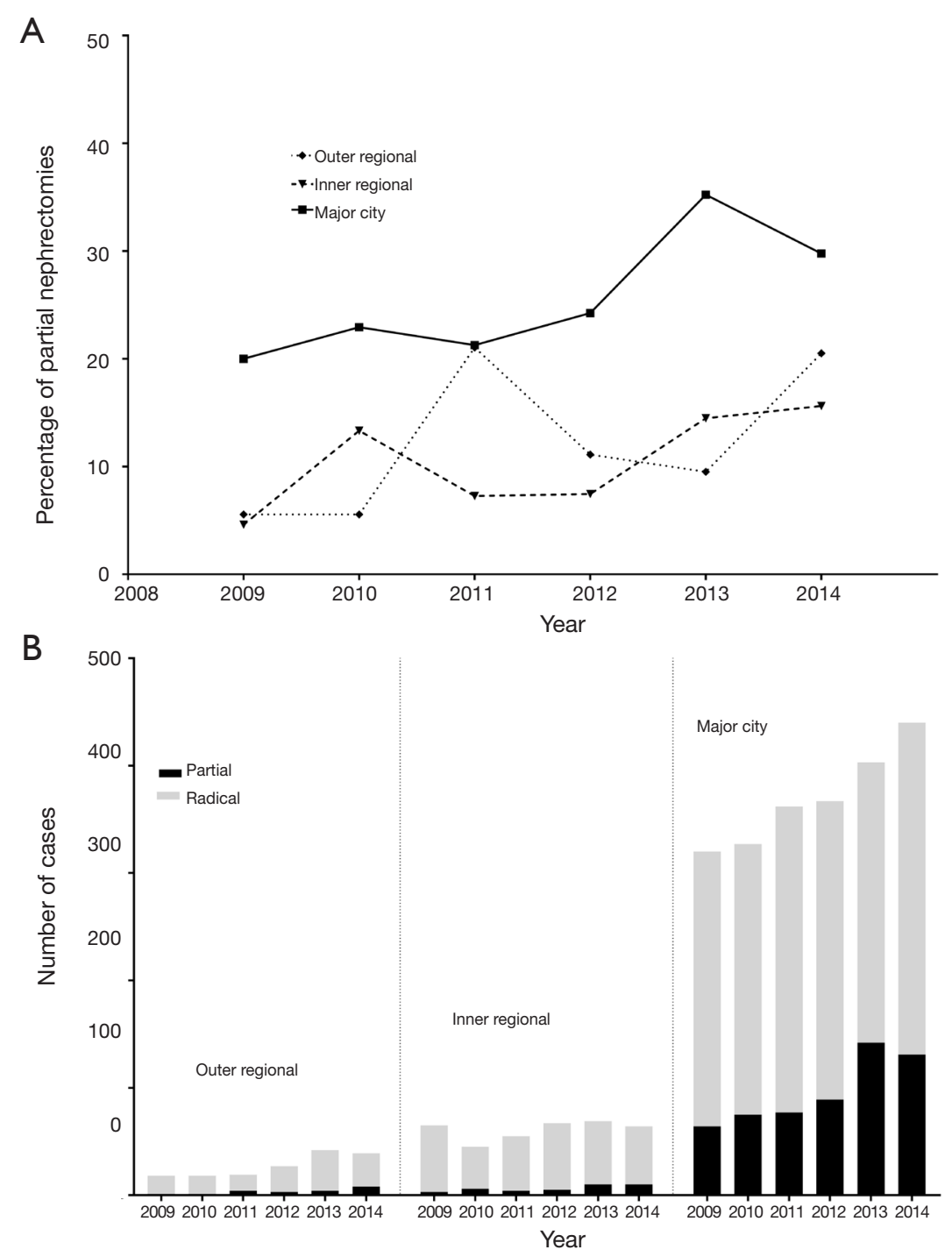

Figure 2 Proportion of patients managed with partial nephrectomy by year. (A) Proportion of patients who underwent surgery who were managed with partial nephrectomy, compared on hospital location; (B) proportion of patients who were managed with partial and radical nephrectomy compared on hospital location, presented as the total number of cases.

1-2 supports the assertion that complex cases were likely to have been referred to larger centres. Despite the fact that partial nephrectomy was generally less likely to be performed in rural hospitals, over time, the number of nephrectomies performed in rural settings has increased, as has the proportion of rural patients who were managed with partial nephrectomy. This reflects global trends favouring nephron-sparing procedures, and indicates that practice is evolving in rural centres, in line with international consensus.
In most regions of Australia, the majority of the population lives within $500 \mathrm{~km}$ of the capital city of a state or territory. Queensland is the exception, where multiple population centres fall outside this $500 \mathrm{~km}$ radius (Figure 3D). This population distribution introduces unique challenges for the public health system, and several factors need to be considered for policy development. These include considerations related to the provision of quality health services that are close to patient's place of residence, minimising transfer and accommodation costs, and 


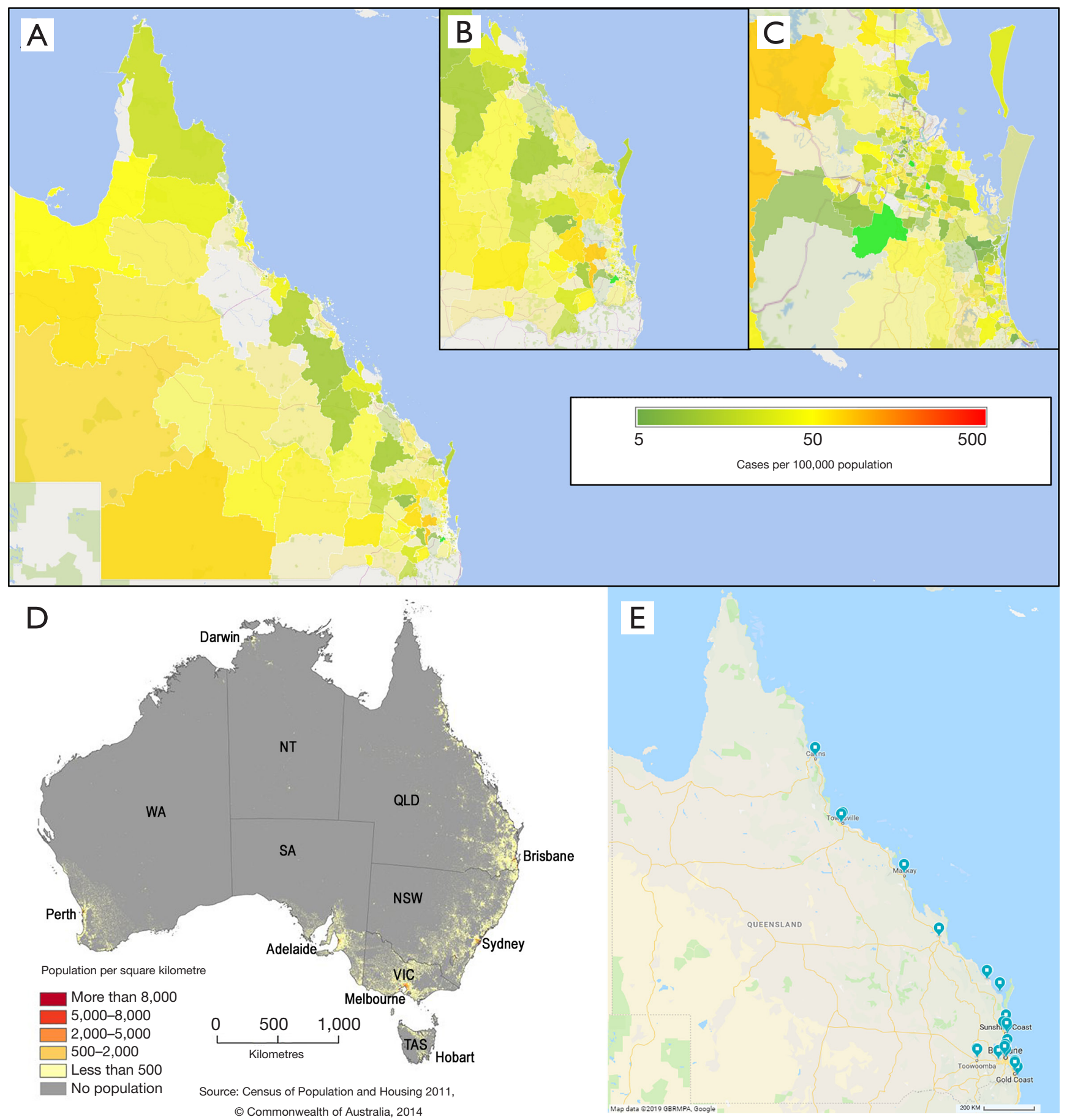

Figure 3 Geographical distribution of kidney cancer in Queensland. (A,B,C) Incident cases of kidney cancer in Queensland compared by region, standardised to the population of each statistical area; (D) map depicting Australia's population density using $1 \mathrm{~km}^{2}$ grids, developed by the Australian Bureau of Statistics. (C) 2014 Commonwealth of Australia. Reproduced under Creative Commons Attribution 4.0 International License; (E) map of hospitals where nephrectomy was performed in Queensland during the study period. Reproduced in accordance with Google Maps Terms of Service (scale bar 200 km). NSW, New South Wales; NT, Northern Territory; QLD, Queensland; SA, South Australia; TAS, Tasmania; VIC, Victoria; WA, Western Australia. 
optimising the quality of health service delivery in regional areas. In terms of kidney cancer surgery in Queensland, these considerations taken together tend to indicate that centralisation is likely not cost-efficient; this is in contrast with states like Victoria, where centralisation of care may be a feasible and cost-effective option, due to the relative proximity of the majority of the population to the state's capital city (Melbourne). Accordingly, the authors advocate for health service policy and delivery models that support regional surgeons.

There were some notable differences in patient characteristics compared between the hospital locations: ASA score, socioeconomic status, and place of residence varied substantially between hospital location. Both socioeconomic status and place of residence are likely attributable to geographical factors, where patients living in rural areas were more likely to be managed at rural hospitals, and areas that are lower socioeconomic status are disproportionately more likely to also be in rural locations (22). The differences in distribution of ASA score are likely to reflect the fact that complex patients were more likely to be managed at tertiary referral centres, which are located in metropolitan areas. This is despite the fact that patients from rural areas tend to have poorer baseline health, higher rates of obesity, and higher incidence of chronic conditions (23).

We also noted a lower likelihood of partial nephrectomy associated with low socioeconomic status, which was consistent with other studies conducted in Australia (15). Notwithstanding, partial nephrectomy was not more likely in private compared with public hospitals, which may be a better measure of individual socioeconomic status compared with area-level indices. Therefore, this result may be more likely to reflect the fact that socioeconomic status is disproportionately lower in rural compared with metropolitan areas, rather than truly reflecting socioeconomic status contributing directly to management.

As patient age increased, the likelihood of partial nephrectomy decreased. This relationship between age and likelihood of partial nephrectomy has been observed in many studies $(8,9,24-26)$, even though complication rates in the elderly are equivalent for radical and partial nephrectomy (27), and some studies have reported survival benefits for partial nephrectomy in older patients (28). A recent study evaluating the use of partial nephrectomy in
956 patients with T1a renal cell carcinoma from Victoria and Queensland managed between January 2012 and December 2013 reported that $32.5 \%$ of patients aged $\geq 65$ yrs underwent partial nephrectomy, compared with $57.5 \%$ of patients aged $\leq 64$ yrs (24).

In this study, $25 \%$ of patients managed surgically for kidney cancer between January 2009 and December 2014 underwent partial nephrectomy. This was comparable to other states in Australia, but lower than other countries such as Canada and the United States (Figure 4) $(8,15,16,20,29,30)$. For example, based on data from the American Board of Urology certification/recertification $\operatorname{logs}, 39 \%$ of patients managed surgically for kidney cancer underwent partial nephrectomy between November 2009 and November 2014 (8). This may reflect a lower tendency for surgeons to perform partial nephrectomy over radical nephrectomy in Queensland. This is consistent with survey data from a recently published study including 32 Queensland urologists, where $77 \%$ agreed that partial nephrectomy was the treatment of choice for T1a renal cell carcinoma (24). The authors of the study speculated that this could have been due to the lack of high-quality evidence favouring partial over radical nephrectomy in international evidence-based guidelines (24).

Strengths of this study include its large sample size and population-based sampling strategy. The major limitation was that characteristics of the tumour were not available, as the tumour size, stage and location is likely to confound the association between hospital location/volume and type of surgery performed. It is also possible that the proportion of higher-stage tumours varies between rural and urban areas, due to differences in healthcare access.

This study confirmed that patients managed surgically for kidney cancer in Queensland who live outside major cities are less likely to be managed with partial nephrectomy, probably due to increased likelihood of being managed at a hospital which is located outside of a major city, where partial nephrectomy is generally performed less frequently, and complex cases amenable to partial nephrectomy are referred to tertiary hospitals. Although patients who are managed outside major cities are less likely to undergo partial nephrectomy, the proportion of patients managed with partial nephrectomy has increased substantially over time from $5 \%$ in 2009 , to almost $20 \%$ in 2014 , indicating substantial changes in practice over time. 


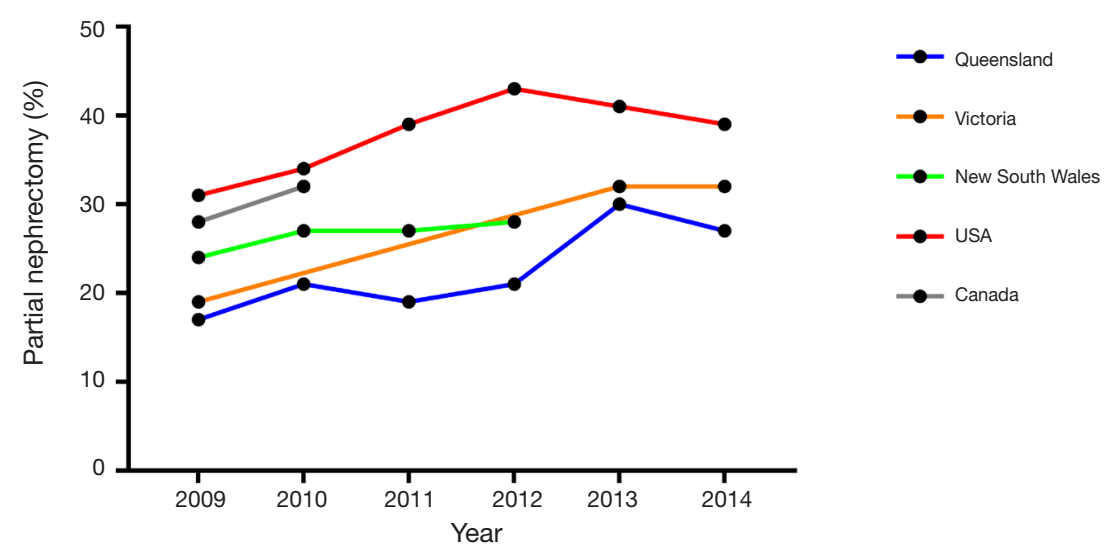

Figure 4 Interstate and international comparisons of partial nephrectomy rates. Proportion of patients managed surgically for incident kidney cancer who underwent partial nephrectomy between 2009 and 2014. Queensland data from the present study. Victorian data from Ta et al. (29) and White et al. (15) with additional data provided by the authors of these papers. New South Wales data from Patel et al. (16) with additional data provided by the New South Wales Clinical Cancer Registry. USA data from Sorokin et al. (8). Canadian data from Yap et al. (30).

\section{Acknowledgments}

Data used in the preparation of this article were obtained from the Queensland Cancer Registry, managed by the Queensland Cancer Control and Analysis Team under the auspices of the Queensland Cancer Control Safety and Quality Partnership, a gazetted quality assurance committee under Part 6, Division 1 of the Hospital and Health Boards Act 2011 (Gazetted 10 December 2004). The Cancer Alliance Queensland contributed data but did not participate in the analysis or writing of this manuscript.

The authors thank Professor Victoria White (Deakin University and Cancer Council Victoria) and the New South Wales Clinical Cancer Registry (Cancer Institute New South Wales) for providing additional data, summarised in Graph 4.

Funding: None.

\section{Footnote}

Data Sharing Statement: Available at http://dx.doi. org/10.21037/tau-19-775

Conflict of Interest: All authors have completed the ICMJE uniform disclosure form (available at http://dx.doi. org/10.21037/tau-19-775). The authors have no conflicts of interest to declare.

Ethical Statement: The authors are accountable for all aspects of the work in ensuring that questions related to the accuracy or integrity of any part of the work are appropriately investigated and resolved. Human research ethics approval for this study was obtained from the University of Queensland (2017001010). An application to access patient data without consent was granted under the Queensland Public Health Act (RD007218). All aspects of this study were conducted in accordance with the Declaration of Helsinki.

Open Access Statement: This is an Open Access article distributed in accordance with the Creative Commons Attribution-NonCommercial-NoDerivs 4.0 International License (CC BY-NC-ND 4.0), which permits the noncommercial replication and distribution of the article with the strict proviso that no changes or edits are made and the original work is properly cited (including links to both the formal publication through the relevant DOI and the license). See: https://creativecommons.org/licenses/by-nc-nd/4.0/.

\section{References}

1. Australian Institute of Health and Welfare. Cancer data in Australia. Canberra: Australian Institute of Health and Welfare, 2018: cat. no. CAN 122.

2. Australian Institute of Health and Welfare. Cancer in Australia 2017. Canberra: Australian Institute of Health and Welfare, 2017: cat. no. CAN 100. 
3. Pierorazio PM, Johnson MH, Patel HD, et al. Management of renal masses and localized renal cancer: systematic review and meta-analysis. J Urol 2016;196:989-99.

4. Kunath F, Schmidt S, Krabbe LM, et al. Partial nephrectomy versus radical nephrectomy for clinical localised renal masses. Cochrane Database Syst Rev 2017;5:CD012045.

5. Campbell S, Uzzo RG, Allaf ME, et al. Renal Mass and Localized Renal Cancer: AUA Guideline. J Urol 2017;198:520-9.

6. Ljungberg B, Bensalah K, Canfield S, et al. EAU guidelines on renal cell carcinoma: 2014 update. Eur Urol 2015;67:913-24

7. Bjurlin MA, Walter D, Taksler GB, et al. National trends in the utilization of partial nephrectomy before and after the establishment of AUA guidelines for the management of renal masses. Urology 2013;82:1283-9.

8. Sorokin I, Feustel PJ, O'Malley RL. National utilization of partial nephrectomy pre- and post- AUA guidelines: is this as good as it gets? Clin Genitourin Cancer 2017;15:591-7.e1.

9. Thompson RH, Kaag M, Vickers A, et al. Contemporary use of partial nephrectomy at a tertiary care center in the United States. J Urol 2009;181:993-7.

10. Huang WC, Atoria CL, Bjurlin M, et al. Management of small kidney cancers in the new millennium: contemporary trends and outcomes in a population-based cohort. JAMA Surg 2015;150:664-72.

11. Zini L, Patard JJ, Capitanio U, et al. The use of partial nephrectomy in European tertiary care centers. Eur J Surg Oncol 2009;35:636-42.

12. Tornberg SV, Kilpeläinen TP, Järvinen P, et al. Renal tumor invasion depth and diameter are the two most accurate anatomical features regarding the choice of radical versus partial nephrectomy. Scand J Surg 2018;107:54-61.

13. Thorstenson A, Harmenberg U, Lindblad P, et al. Impact of quality indicators on adherence to National and European guidelines for renal cell carcinoma. Scand J Urol 2016;50:2-8.

14. Lawson KA, Saarela O, Liu Z, et al. Benchmarking quality for renal cancer surgery: Canadian Kidney Cancer information system (CKCis) perspective. Can Urol Assoc J 2017;11:232-7.

15. White V, Marco DJT, Bolton D, et al. Trends in the surgical management of stage 1 renal cell carcinoma: findings from a population-based study. BJU Int 2017;120
Suppl 3:6-14.

16. Patel MI, Strahan S, Bang A, et al. Predictors of surgical approach for the management of renal cell carcinoma: a population-based study from New South Wales. ANZ J Surg 2017;87:E193-8.

17. Ali S, Ahn T, Papa N, et al. Changing trends in surgical management of renal tumours from 2000 to 2016: a nationwide study of Medicare claims data. ANZ J Surg 2020;90:48-52.

18. Ellis RJ, Edey DP, Del Vecchio SJ, et al. End-stage kidney disease following surgical management of kidney cancer. Clin J Am Soc Nephrol 2018;13:1641-8.

19. Australian Bureau of Statistics. Remoteness Structure. Australian Statistical Geography Standard (ASGS). Canberra: Australian Bureau of Statistics, 2011: cat. no. 1270.0.55.005.

20. Australian Bureau of Statistics. Socio-Economic Indexes for Areas (SEIFA). Canberra: Australian Bureau of Statistics, 2013: cat. no. 2033.0.55.001.

21. Bourke L, Humphreys JS, Wakerman J, et al. Understanding rural and remote health: a framework for analysis in Australia. Health Place 2012;18:496-503.

22. Australian Bureau of Statistics. Census of Population and Housing: Reflecting Australia - Stories from the Census, 2016. Canberra: Australian Bureau of Statistics, 2018: cat. no. 2071.0 .

23. Australian Institute of Health and Welfare. Australia's health 2018. Canberra: Australian Institute of Health and Welfare, 2018: Australia's health series no. 16, AUS 221.

24. White VM, Marco DJT, Bolton D, et al. Age at diagnosis and the surgical management of small renal carcinomas: findings from a cross-sectional population-based study. BJU Int 2018;122 Suppl 5:50-61.

25. Dulabon LM, Lowrance WT, Russo P, et al. Trends in renal tumor surgery delivery within the United States. Cancer 2010;116:2316-21.

26. Baillargeon-Gagné S, Jeldres C, Lughezzani G, et al. A comparative population-based analysis of the rate of partial vs radical nephrectomy for clinically localized renal cell carcinoma. BJU Int 2010;105:359-64.

27. Lowrance WT, Yee DS, Savage C, et al. Complications after radical and partial nephrectomy as a function of age. J Urol 2010;183:1725-30.

28. Takagi T, Kondo T, Iizuka J, et al. Comparison of survival rates in stage 1 renal cell carcinoma between partial nephrectomy and radical nephrectomy patients according to age distribution: a propensity score matching study. BJU 
Int 2016;117:E52-9.

29. Ta AD, Bolton DM, Dimech MK, et al. Contemporary management of renal cell carcinoma (RCC) in Victoria: implications for longer term outcomes and costs. BJU Int 2013;112 Suppl 2:36-43.

Cite this article as: Forbes MK, Owens EP, Wood ST, Gobe GC, Ellis RJ. Variability in surgical management of kidney cancer between urban and rural hospitals in Queensland, Australia: a population-based analysis. Transl Androl Urol 2020;9(3):1210-1221. doi:10.21037/tau-19-775
30. Yap SA, Finelli A, Urbach DR, et al. Partial nephrectomy for the treatment of renal cell carcinoma (RCC) and the risk of end-stage renal disease (ESRD). BJU Int 2015;115:897-906. 